\title{
How We Got a $75.4 \%$ Response Rate on an Internet Survey
}

\section{Jill Rosenbaum, B.A. and Charles W. Lidz, Ph.D.}

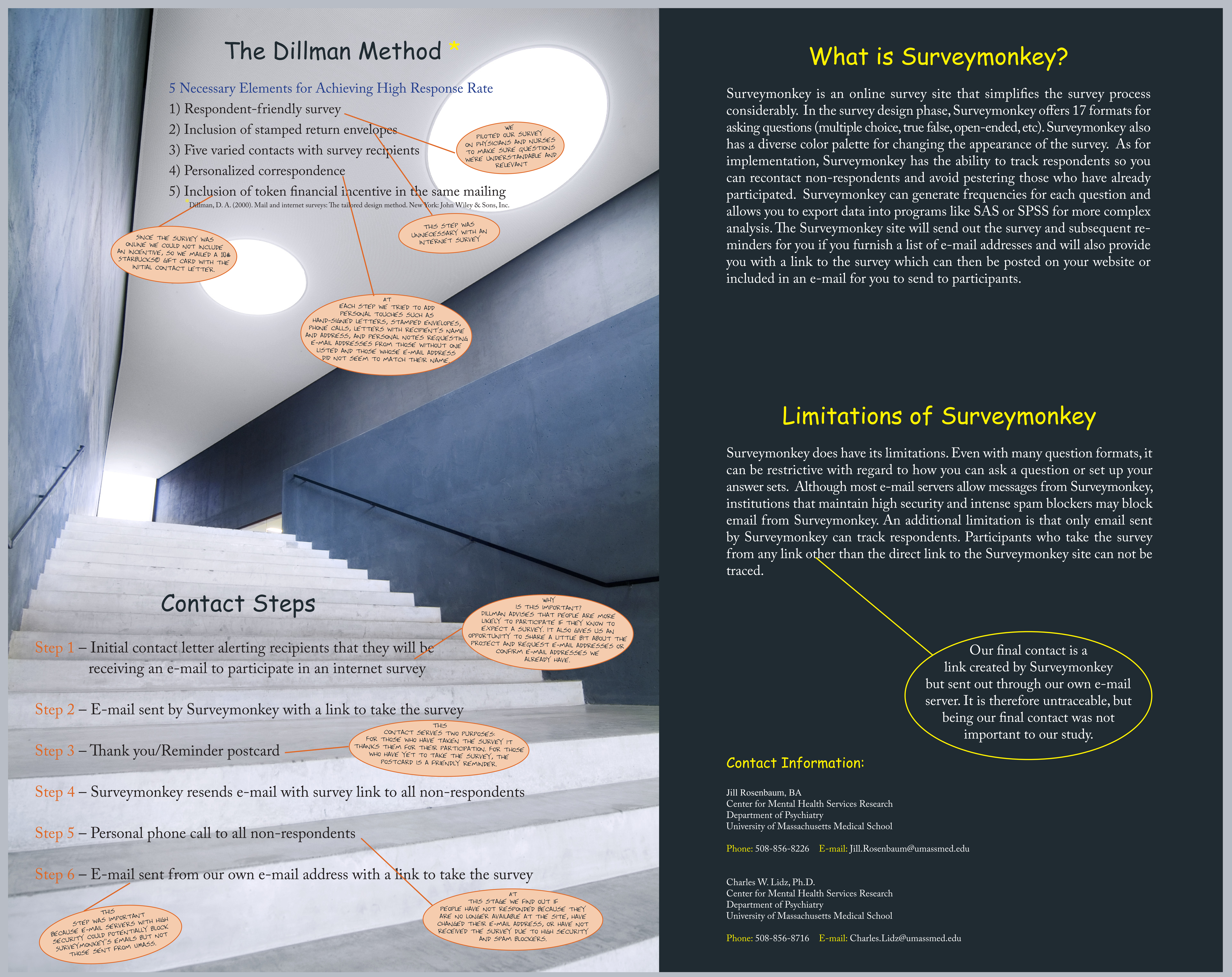

